See Article page 274 .

\section{Commentary: Studying studying}

\author{
Edward Y. Sako, MD, PhD
}

In this edition of JTCVS Open, Doty and colleagues ${ }^{1}$ attempt to examine the benefit of an organized review course in cardiothoracic surgery, specifically its value in preparation for the American Board of Surgery (ABTS) Qualifying Examination. In this study, which the authors admittingly call "quasi-experimental," they looked at the results of a pre- and post-test given in conjunction with a yearly, 4-day course consisting of lectures covering the "core" concepts of the field. Additional multimedia study materials are provided. Of note, this study involved only 1 year out of a course that has been in existence since 1992. Of the participants who took both tests (neither was mandatory), the median score improved by $14 \%$. The authors concluded that the course was successful in improving performance, at least on the tests they put together and administered.

What is still not shown, however, is the ultimate question of whether and to what degree such a review course contributes to one's ability to pass the ABTS examination. Given the large number of factors that enter into this, it would seem to be very difficult and impractical to answer this question. These factors include variability in didactic learning among training programs, individual study habits and test-taking abilities, and time available for examination preparation.

Within the study itself, there are some issues that detract from the central question. All test items were developed or reviewed by practicing ABTS surgeons who have therefore been through the examination process. Each item is linked to a specific major review topic. However, the validity and

\footnotetext{
From the Department of Cardiothoracic Surgery, University of Texas Health Science Center at San Antonio, San Antonio, Tex.

Disclosures: E.Y.S. has a financial relationship with Medtronic, Inc.

The Journal policy requires editors and reviewers to disclose conflicts of interest and to decline handling or reviewing manuscripts for which they may have a conflict of interest. The editors and reviewers of this article have no conflicts of interest.

Received for publication July 29, 2021; revisions received July 29, 2021; accepted for publication July 30, 2021; available ahead of print Aug 17, 2021.

Address for reprints: Edward Y. Sako, MD, PhD, Department of Cardiothoracic Surgery, University of Texas Health Science Center at San Antonio, Mail Code 7841, 7703 Floyd Curl Dr, San Antonio, TX 78229-3900 (E-mail: sako@uthscsa.edu). JTCVS Open 2021;7:286

2666-2736

Copyright (C 2021 The Author(s). Published by Elsevier Inc. on behalf of The American Association for Thoracic Surgery. This is an open access article under the CC BY-NC-ND license (http://creativecommons.org/licenses/by-nc-nd/4.0/).

https://doi.org/10.1016/j.xjon.2021.07.033
}

Check for updates

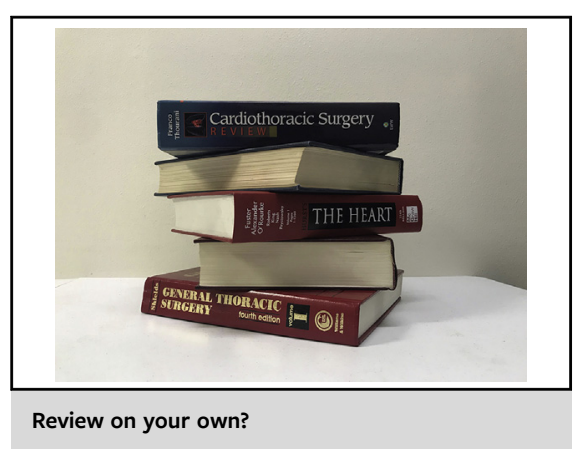

CENTRAL MESSAGE

The true value of an externally organized review of the knowledge base of cardiothoracic surgery remains an individual one.

difficulty of the tests in relation to the Qualifying Exam is unknown. Although the course has been offered for many years, the authors have chosen to look at only a 1-year cohort. As with most studies, larger numbers would be more elucidating. It would also help to increase test validity and reliability. These numbers are further reduced in that less than one half of all participants in the course completed both pre- and post-tests, thus increasing the potential for selection bias. It begs the question of the degree of course participation by individuals and how this may have reflected in test results. There is also potential for familiarity with the test that may contribute to improved performance, and this is acknowledged by the authors.

Ultimately, the value of such a course is in the eye of the participant. Having a structured, all-encompassing review is of benefit to anyone preparing for an examination. Key among these is the identification of areas of weakness and the organized encouragement to set aside the needed time for preparation.

\section{Reference}

1. Doty JR, Nguyen M, Snyder RJ, McCann UG, Doty DB. Impact of a focused review course in cardiovascular and thoracic surgery on test performance. J Thorac Cardiovasc Surg Open. 2021;7:274-85. 